\title{
Search behaviour of two hemipteran species using vibrational communication
}

\author{
Research Article
}

\author{
Maarten de Groot ${ }^{1,2, *}$, Andrej Čokl' , Meta Virant-Doberlet ${ }^{1}$ \\ ${ }^{1}$ National Institute of Biology, 1000 Ljubljana, Slovenia \\ ${ }^{2}$ Slovenian Forestry Institute, 1000 Ljubljana, Slovenia
}

Received 02 March 2011; Accepted 19 May 2011

\begin{abstract}
The ability of conspecifics to recognize and locate each other in the environment depends on the efficiency of intraspecific communication. We compared the mate searching strategies of southern green stinkbug Nezara viridula (male searches for a continuously calling female) and the leafhopper Aphrodes makarovi (partners form a precisely coordinated duet). Males of both species were tested on plants in playback experiments. One leaf was vibrated with unaltered conspecific female signals or with various conspecific signals using modified temporal parameters. The results showed that the onset of searching was faster in $A$. makarovi than in N. viridula. Changes in temporal parameters of female replies had negative effect on the searching behaviour of $A$. makarovi. Males located the source of longer female replies faster than the short female call and they failed to locate the source of a female reply with temporal parameters outside the species-specific values. In contrast, in N. viridula, searching males successfully located also the source of a female song with parameters outside the species-specific values. The results are discussed with regard to male behavioural strategies in species with different vibrational communication systems and different male mating investment.
\end{abstract}

Keywords: Mating systems • Mate location • Recognition • Mate choice

(C) Versita Sp. z 0.0 .

\section{Introduction}

Finding the right partner is central to an animal's reproductive success [1-3]. Although the searcher's gender differs among mating systems [4], higher searching effort is typically found in males [5]. While searching effort is defined as activity that increases the probability of encountering a mate and includes displays to attract a potential partner (i.e. acoustic and/or chemical signals) as well as mobility needed to increase the signalling space and/or locate the mate [6], searching is usually used to describe the movements associated with approach to the partner. While the probability of finding a female increases with time spent searching [2], longer searching time also increases energy expenditure [7] and male mortality [8]. Taking into account costs associated with searching, it is advantageous for a male to recognize a conspecific female in an early step of the courtship and then locate her as fast as possible.

The ability of conspecifics to recognize and locate each other in the environment depends on the efficiency of intraspecific communication. In particular, speciesspecific signals used in sexual communication enable identification of the sender (species and sex) and provide information necessary to determine its location (e.g. $[9,10])$. Insects have evolved a great variety of chemical, visual and mechanical (air-borne sound and substrateborne vibrations) signals for intraspecific communication [11]. For insects using air-borne sound communication to find a mate, two long-range communication systems have been described. Unidirectional communication is common in crickets and many bush-crickets [10]. In this system, a silent female searches for a continuously singing conspecific male. Bidirectional communication systems have been described in some bush-crickets and grasshoppers [10]. In this case the male signals trigger the reply from the conspecific female and afterwards either the male or the female searches for the partner.

Although substrate-borne vibratory signalling is prevalent among insects, it received much less attention than air-borne sound communication that is restricted to only few insect groups [11-13]. In Hemiptera vibrational signalling is a common type of communication $[11,13]$. 
This group comprises around 94,000 species [14-16]. Two vibrational communication systems commonly found in Hemiptera are similar to the previous two systems described in air-borne sound communication. The communication system of the southern green stink bug Nezara viridula (L.) has been used as a model for the whole family Pentatomidae [17]. Although both sexes emit vibrational signals (termed songs) [18], the vibrational communication in this species resembles a unidirectional system in two important ways. First, a stereotyped male-female duet is not formed during the initial advertising stage (Figure 1A). One partner (male in this case) identifies another one (the female) via the temporal pattern of her continuously emitted calling song and locates her on the plant [19-22]. Second, male vibrational signals do not trigger female calling [21], while females emit their calling song continuously with stable signal repetition rate for several minutes in the absence of male vibrational signals [23,24]. Emission of female vibrational signals is triggered by male sex pheromone [23] and the female calling song, in turn, triggers the emission of male courtship song [17] and searching behaviour [19]. The role of male vibrational signals and importance of their specificity during the initial advertising and searching stage is not clear [17] however, they may provide the information for the female that male is on the same plant and thus help to maintain the emission of female calling song for a longer time to enable successful localization.

The typical bidirectional communication system in which male calls and female reply triggers male searching behaviour is, among other, found in leafhoppers (Cicadellidae) [25,26]. In contrast to the unidirectional system, the bidirectional communication system requires a precisely coordinated male-female duet for successful localization of a partner (Figure 1B) [27-29]. The leafhopper Aphrodes makarovi Zachvatkin shows typical leafhopper mating behaviour (de Groot et al., submitted for publication). Males increase their signalling space by the 'call-fly' strategy that is common among Auchenorrhyncha [30-32]. When the male arrives to the plant, it starts to call and in the absence of a female reply, it moves to another plant. A stationary receptive female present on a plant replies and after establishing a duet, the male starts searching on a plant and locates the female. The female response always overlaps the end of the male call and consequently, the female reply delay as measured from the end of the male signal - is short, less than $50 \mathrm{~ms}$ (Figure 1B). Females of $A$. makarovi vary the duration of their reply according to duration of the male call to which they are responding (de Groot et al., submitted for publication). In a communication system in which the duration of the female reply may be crucial for quickly locating the female, variation in duration may indicate female preference and choice.

In this study we examine the influence of speciesspecific temporal parameters of the female vibrational signals on the searching behaviour in $N$. viridula and A. makarovi. Males of both species were tested in playback experiments and we recorded their behaviour in response to conspecific female vibrational signals with modified temporal parameters. According to the differences in communication system between $N$. viridula and $A$. makarovi, changes in temporal parameters should have different effect on males of both species. Compared to the female vibrational signals of closely related pentatomid or leafhopper species, the calling songs of $N$. viridula and $A$. makarovi are variations on the same basic pattern [17] (Bluemel et al., in preparation). However, in a bidirectional communication system, recognition of the male call is a prerequisite for a properly timed reply emitted by the conspecific female and as in other leafhoppers, male calling signals of species in the genus Aphrodes are complex and differ substantially in their structure [33,34] (Bluemel et al., in preparation). We predict that in $A$. makarovi a female reply linked
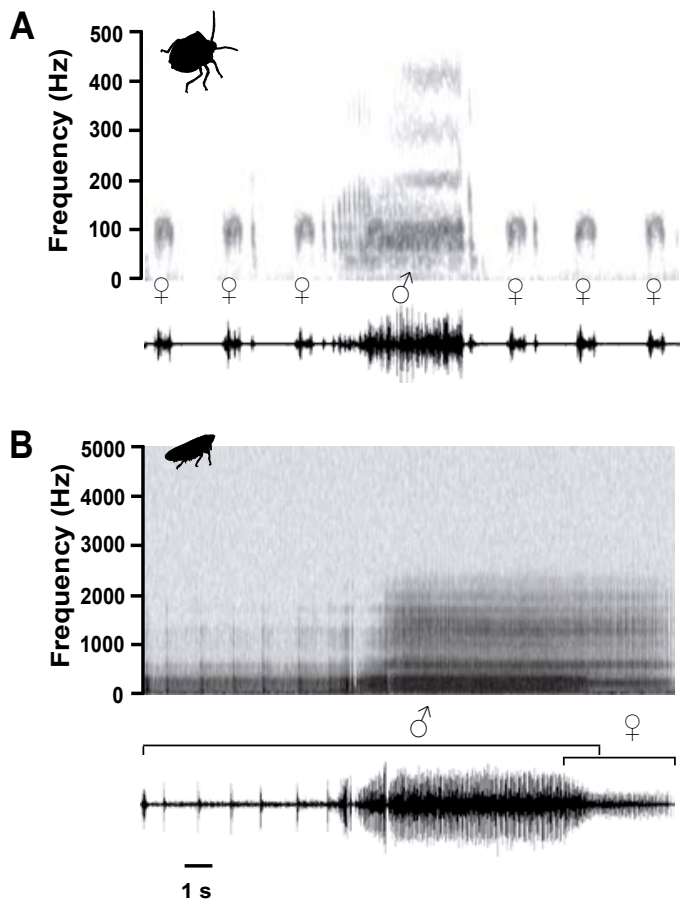

Figure 1. Vibrational signals of Nezara viridula (A) and Aphrodes makarovi (B). In N. viridula male vibrational signal (male courtship song) is emitted sporadically, while female calling song is emitted continuously with stable signal repetition rate. In A. makarovi male and female establish a stereotyped duet in which female reply overlaps the end of male call. $\delta$ and $q$ indicate the male and female signals, respectively. Sonagram (above) and oscillogram (below) are shown. 
to male calling signal allows males a fast onset of searching behaviour. If the only cue for triggering male searching is the response time window, the change in the species-specific pulse repetition time of the female signal or in the signal duration should have no effect on male searching behaviour. On the other hand, if A. makarovi males have to identify a conspecific female call by temporal parameters, changes should have a negative effect on searching behaviour. In this species a longer female reply should enable faster location of the female because it provides better directional information. In contrast, we predict that males of $N$. viridula need more time to start searching since in the absence of a predictable temporal association between partners' signals, they initially have to invest more time in recognition. However, after the search is triggered, in continuous presence of the female song, changes in temporal parameters of the female song should have little effect on searching behaviour. Female songs with longer signals or with higher signal repetition time may provide better directional information.

\section{Experimental Procedures}

\subsection{Insects and plants \\ 2.1.1 Nezara viridula}

Adult bugs were collected in late autumn (OctoberNovember) at the Slovenian North Adriatic coast. The bugs were kept separated by sex in the laboratory under diapause conditions $\left(8 \mathrm{~h} / 16 \mathrm{~h}\right.$ L/D cycle at $\left.5-10^{\circ} \mathrm{C}\right)$ for at least one month. To ensure their sexual activity, the diapausing animals were transferred to normal conditions (16 h/8 h L/D cycle at $22-23^{\circ} \mathrm{C}$ and $70-80 \%$ relative humidity) at least 10 days before the beginning of behavioural tests. Each male was kept separately in a plastic pot $(14 \mathrm{~cm}$ high, $6 \mathrm{~cm}$ diameter at the bottom and $10 \mathrm{~cm}$ diameter at the top) and fed with raw peanuts (Arachis hypogaea L.), sunflower seeds (Helianthus annuus L.) and growing dwarf bean (Phaseolus vulgaris L.). In addition, some animals were used to establish a laboratory colony. They were reared in glass boxes $(38 \times 23 \times 23 \mathrm{~cm})$ on a diet described above. Adult males from laboratory colony were kept in separate pots as described above and were used for behavioural tests 10 days after the final moult to ensure their sexual maturity.

Bean plants are one of the preferred host plants of $N$. viridula [35] and the experiments were performed on dwarf French beans var. etna (Phaseolus vulgaris L.) grown in the laboratory. They were planted in peat soil in plastic pots (pot dimensions as above) and watered three times a week. Plants used in behavioural tests were at least 10 days old. The test plants were $20-30 \mathrm{~cm}$ high and consisted of the middle stem and one junction formed by left and right side branch, each with a single leaf (Figure 2A). The junction was located approximately seven $\mathrm{cm}$ below the tip of the plant. At the top of the middle stem was a branch with three leaves. Different plants were taken every two days.

\subsubsection{Aphrodes makarovi}

Adult leafhoppers were collected in June in the Dragonja valley in south west Slovenia. Since in genus Aphrodes morphological characters used to separate species relate to internal male genital morphology, species was determined by recording the vibrational signals with laser vibrometer (see below), and comparing them with known signals [33,34]. Males were placed individually in plastic pots (pot dimensions as above) two days before the experiments. They were fed with the plants on which they were found: alfalfa (Medicoga sativa), red clover (Trifolium pratense) and stinging nettle (Urtica dioica).

Experiments were performed on stinging nettle. The upper part (height $30 \mathrm{~cm}$ ) was cut from a wild plant and planted into a peat soil in plastic pots (pot dimensions as above). All leaves, except the top ones and the fourth pair counting from the top, were cut off (Figure 2B). The leaf junction was located approximately seven centimetres below the tip of the plant. Different plant was taken every day.

\subsection{Vibrational stimuli \\ 2.2.1 Nezara viridula}

Males of $N$. viridula were tested with four different stimulation sequences (Table 1). Each stimulatory sequence was composed from natural vibrational signals assembled by the use of the computer programme
A

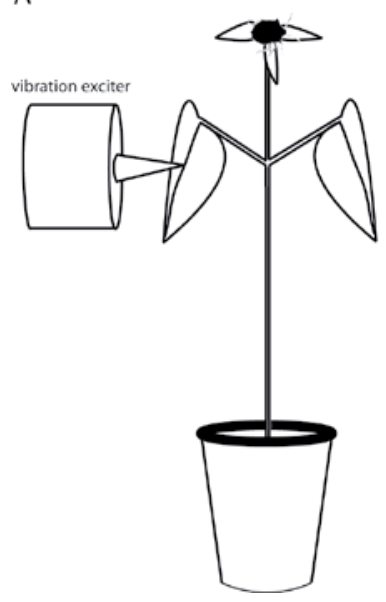

B

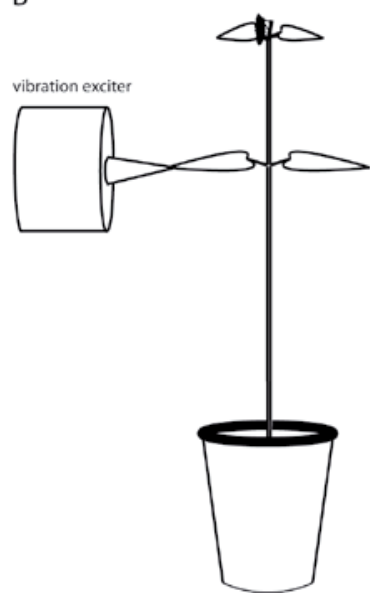

Figure 2. A schematic drawing of the experimental set-up, showing the initial position of the male on the top of the plant and the position of vibration exciter (not to scale). (A) Nezara viridula; (B) Aphrodes makarovi. 
Cool Edit Pro 2 (Syntrilium Software, Phoenix, USA). The stimulation sequence with natural $N$. viridula female calling song $\left(\mathrm{FCS}_{\mathrm{Nv}}\right)$ consisted of an unmodified sequence of 39 signals emitted by one female (sequence duration $130 \mathrm{~s}$ ). The spectral characteristics and temporal parameters had mean values that correspond to the preferred values of males from Slovenian population $[20,36,37]$. The natural sequence was recorded from the membrane of the low-middle frequency loudspeaker membrane (Conrad Electronic, impedance $8 \mathrm{~W}, 4.5 \mathrm{~mm}$ diameter, $90-2000 \mathrm{~Hz}$ ) with a laser vibrometer (controller 2200-L, sensor head OFV353, Polytech, GmbH, Waldbronn, Germany) and stored in a computer using Sound Blaster Audigy 4 sound card (Creative Labs Inc.) and Cool Edit Pro 2 software at the sampling rate of $44100 \mathrm{~Hz}$. We altered the above mentioned $\mathrm{FCS}_{\mathrm{Nv}}$ stimulation sequence with Cool Edit Pro software to obtain sequences with different temporal parameters (Table 1). To obtain the stimulation sequence $\mathrm{FCS}_{\mathrm{Nv} \text {-short }}$ we cut out $320 \mathrm{~ms}$ of each signal (starting at $220 \mathrm{~ms}$ from the beginning of the signal) in $\mathrm{FCS}_{\mathrm{Nv}}$ sequence, while the stimulation sequence $\mathrm{FCS}_{\mathrm{Nv}-\mathrm{Iong}}$ was created by extending each signal by copying $300 \mathrm{~ms}$ of the signal (starting at $220 \mathrm{~ms}$ from the beginning of the signal). While the duration of short signals was outside species-specific values, the duration of long signals was within species-specific parameters [18,21]. The duration of the interval was adjusted, so that the signal period (i.e. signal repetition time) remained the same. Stimulation sequence $\mathrm{FCS}_{\mathrm{Nv} \text {-ast }}$ was composed by copying and pasting signals in the middle of each interval (Table 1). The signal repetition time within this sequence was outside species-specific values [18,21]; however, song with higher signal repetition time may enable faster localization of the source. Each of the above mentioned stimulation sequences was played back in a continuous loop for the duration of the stimulation period (see below).

\subsubsection{Aphrodes makarovi}

Males of $A$. makarovi were tested with five different female calls (Table 2). All female signals were composed from natural pulses assembled by the use of the Cool Edit Pro 2 computer programme. Four pulses were taken from the natural female call recorded on an alfalfa plant five $\mathrm{cm}$ from the calling female with the laser vibrometer mentioned above. Since female reply always overlaps the male call, pulses were taken from the section of immediately after the end of the male signal. In one composed female call $\left(\mathrm{FC}_{\mathrm{Am}}\right)$, all values corresponded to the mean values of the non-overlapping part of the female call determined for $A$. makarovi females (de Groot et al., submitted for publication). It has been shown that this composed female call triggers the same male behaviour as observed in natural male-female duets (de Groot et al., submitted for publication). One composed female call $\left(\mathrm{FC}_{\mathrm{Am} \text {-short- } \mathrm{N}}\right)$ represented a shorter female reply within the natural range of temporal parameters (de Groot et al., submitted for publication), while another one $\left(\mathrm{FC}_{\text {Am-short-sN }}\right)$ represented shorter-than-natural female call. $\mathrm{FC}_{\mathrm{Am}}$ was composed from 188 pulses, while the shorter calls contained 94 and 47 pulses, respectively. The $\mathrm{FC}_{\text {Am-fast }}$ call was obtained by doubling the pulse repetition rate within the female call. A continuous female call $\left(\mathrm{FC}_{\mathrm{Am}-\mathrm{cont}}\right)$ was obtained by playing the middle part of the

\begin{tabular}{l|ccc}
\hline & Signal duration (s) & Signal repetition time (s) & Dominant frequency (Hz) \\
\hline \hline FCS & $0.70 \pm 0.01$ & $2.64 \pm 0.03$ & $116 \pm 0.1$ \\
FCS $_{\text {Nv-ast }}$ & $0.70 \pm 0.01$ & $1.30 \pm 0.02$ & $116 \pm 0.1$ \\
FCS $_{\text {Nv-short }}$ & $0.38 \pm 0.01$ & $2.64 \pm 0.03$ & $108 \pm 0.1$ \\
FCS $_{\text {Nv-long }}$ & $1.033 \pm 0.02$ & $2.64 \pm 0.03$ & $116 \pm 0.1$ \\
\hline
\end{tabular}

Table 1. Temporal and spectral characteristics of natural and modified calling songs of Nezara viridula female used in stimulation sequences Means \pm s.e.m. are shown.

\begin{tabular}{l|ccc}
\hline & Call duration (s) & Pulse repetition time (s) & Dominant frequency (Hz) \\
\hline \hline$F C_{\text {Am }}$ & 10.4 & 0.052 & 308 \\
$F C_{\text {Am-short-N }}$ & 5.2 & 0.052 & 308 \\
$F C_{\text {Am-short-SN }}$ & 2.6 & 0.052 & 308 \\
$F C_{\text {Am-ast }}$ & 5.2 & 0.026 & 308 \\
$F C_{\text {Am-cont }}$ & 780.0 & 0.052 & 308 \\
\hline
\end{tabular}

Table 2. Temporal and spectral characteristics of calls of Aphrodes makarovi female used for stimulation. Means \pm s.e.m. are shown. 
signal with natural parameters in a loop for 13 minutes (see below). Although the duration of the continuous call is outside species-specific values, it may provide better directional information.

\subsection{Experimental setup and protocol}

\subsubsection{Nezara viridula}

All behavioural tests on $N$. viridula males were performed on a bean plant at the room temperature $\left(24^{\circ} \mathrm{C}\right)$ and $40-50 \%$ relative humidity. We applied vibratory stimuli to the middle vein on the proximal third of the leaf via a tip of the cone screwed firmly into the head of a vibration exciter (minishaker type 4810, Brüel and Kjaer, Naerum, Denmark) (Figure 2). The side of stimulation was changed four times a day. The vibratory stimuli and male vibrational responses were recorded from the main stem $1 \mathrm{~cm}$ above the branching point by the laser vibrometer mentioned above. The amplitude of stimulation was adjusted to the level of the recorded signals emitted by responding males. Signals were digitized with $48 \mathrm{kHz}$ sample rate and 16 depth and stored onto a hard drive of a PC computer with an external sound card (Sound Blaster Extigy, Creative Labs Inc.) using Cool Edit Pro 2 software. Behaviour was filmed with a $3 C C D$ video camcorder (Canon DM XM2) which was fitted with a 4.2-84 $\mathrm{mm}$ zoom lens and analysed with Microsoft Windows movie maker 5.1 .

In all experiments a $N$. viridula male was placed on the top of the plant and after 2 minutes we applied natural female calling song for 2 minutes in order to check the daily general responsiveness of each male (i.e. whether they responded to conspecific female calling song on the day of a particular treatment). It has been shown that pre-stimulation with conspecific female calling song did not significantly affect male responsiveness [38]. After a 2 min silent pause we applied stimulation sequence for 13 minutes. If the male located the source, the trial was terminated earlier (see below). Each male was tested once with each stimulatory sequence and their order was randomized for each male. Each male was tested only once per day.

We monitored the following parameters that were used to describe male mate searching behaviour in $N$. viridula in previous studies [19-22]: number of males emitting vibrational signals (male courtship song [18]), duration of male courtship song, number of males searching (defined as singing and moving [19]), number of signals emitted during walking, search latency (time needed to start moving after the start of stimulation), number of males locating the vibration source and searching time (time needed to locate the source after the onset of searching). The male was recorded as locating the source if he reached the exciter or the top of the vibrated leaf and stayed there for 3 min or until the end of the trial, whichever came first. The cumulative signalling duration for males and females was defined as the cumulative time that vibrations of males and females were present from the beginning of stimulation until the male located the source of vibrations. The cumulative signalling duration for females was taken from the signals used in stimulation sequences.

\subsubsection{Aphrodes makarovi}

All behavioural tests with $A$. makarovi males were performed on a stinging nettle under the same conditions as described above for $N$. viridula. We applied vibratory stimuli to the tip of the leaf using a vibrational exciter as mentioned above (Figure 2). The vibratory stimuli and responses of the leafhoppers were recorded from the main stem $1 \mathrm{~cm}$ above the branching point by laser vibrometer as described above and the amplitude of stimulation was adjusted to the level of the recorded female signals. Vibrational signals and behaviour were recorded and analysed as described for $N$. viridula. In addition, the program Jwatcher 1.0 (http://www.jwatcher.ucla.edu/) was used to record the type and time of behaviour.

In total, $15 \mathrm{~A}$. makarovi males were tested. In all experiments a male was placed on the top of the nettle. After two minutes we applied pre-recorded a malefemale duet in order to induce male calling. When the male on the plant emitted a call, we presented him with a female reply. The application of a female reply was triggered manually and we timed the onset of a female reply with the typical decrease in amplitude in the last part of the male call (Figure 1). This corresponds to the natural timing of female response (de Groot et al., submitted for publication). The artificial duet was maintained for 13 minutes or until the male located the source of vibrations, whichever came first. In control experiments males were stimulated after two minutes with pre-recorded male-female duet to induce calling however, after they emitted a call, they received no female reply and afterwards their behaviour was observed for 13 minutes in the absence of stimulation. Each male was tested only once per day. Each male was tested once with each female call and their order was randomized for each male.

In all experiments we monitored the following parameters: number of calls emitted by males and we expressed calling activity as call rate (calculated number of calls per min during the stimulation period), duration of male calls, number of males searching (defined as walking during female call), number of male calls emitted during walking, search latency (time needed to start moving after the end of male call), number of males locating the vibration source and searching time (time 
needed to locate the source after the onset of searching). We expressed male signalling activity as call rate and not as a proportion of calling males (see Results) since in all treatments all males were calling (see above). The male was recorded as locating the source if he reached the exciter or the top of the vibrated leaf and stayed there for $3 \mathrm{~min}$ or until the end of the trial, whichever came first. The cumulative signalling duration for males and females was defined as the cumulative time that vibrations of males and females were present from the first presentation of female reply in response to male call until the male located the source of vibrations. The cumulative signalling duration for females was taken from calls used for stimulation.

\subsection{Analyses}

\subsubsection{Nezara viridula}

For $N$. viridula we included in the analyses only males that showed positive general responsiveness (i.e. they responded to pre-stimulation with conspecific female calling song on the day of a particular treatment). The number of males included in the analyses, after excluding the false negative responses for each treatment, is shown in Figure 3. Only males that located the source were included in the analysis of cumulative signalling duration.

We compared the values obtained in each treatment with values obtained in treatment with $\mathrm{FCS}_{\mathrm{Nv}}$. To compare the differences in the number of males singing, and locating the source we used a Chi-square test for contingency tables [39] followed by Ryan's multiple comparison test of proportions [40]. Duration of male courtship song, searching latency, search time and cumulative signalling duration were compared with Kruskal-Wallis test followed by the Steel multiple comparison test [41].

\subsubsection{Aphrodes makarovi}

For A. makarovi 11-13 males were included in the analyses for each treatment. The numbers of males used in the analyses of each treatment are shown in Figure 4. Only males that located the source were included in the analysis of cumulative signalling duration.

We compared the values obtained in each treatment with values obtained in treatment with $\mathrm{FC}_{\mathrm{Am}}$. To analyse differences in call rate, call duration, proportion of males searching per female reply and search latency we used Kruskal-Wallis test followed by Steel multiple comparison test [41]. The difference in search latency between the first male call and the following ones in the treatment with a continuous $A$. makarovi female reply was tested with Wilcoxon matched-pairs signed-ranks test [39]. To compare the differences in the number of males locating the source we used a Chi-square test for contingency tables [39] followed by Ryan's multiple comparison test of proportions [40]. Since in A. makarovi only in two treatments more than one male located the source, difference in searching time between these two treatments was analysed with Mann Whitney $U$ test [39]. We compared the cumulative signalling duration between males and females in these two treatments with Wilcoxon matched-pairs signed-ranks test. In addition, we compared the cumulative signalling durations of males and females between the two treatments using Mann Whitney U test.

\section{Results}

\subsection{Nezara viridula}

Males responded to stimulation by natural and modified conspecific female song with emission of male courtship song and searching behaviour. Not all males that responded with vibrational signals started searching; however, majority of searching males located the source. As described previously, males were stopping regularly while searching $[19,42]$. When they reached the junction between the main stem and leaf stalks they stopped with legs placed on different branches. After several seconds, during which they perceived another signal in female calling song, they continued walking. Searching males sporadically emitted vibrational signals and $20 \%$ of signals were emitted while males were walking. When males arrived at the vibrational source, they continued to search either on the leaf or on the vibration exciter.

The number of calling males differed significantly among treatments $\left(X^{2}=18.25, \quad d f=3, \quad P<0.001\right)$. Compared to the unaltered conspecific female calling song, significantly lower number of males started to call when stimulated with songs composed from signals with shorter duration (Ryan's test, $P<0.05$; Figure $3 \mathrm{~A}$ ) or faster repetition rate (Ryan's test, $P<0.05$ ). The number of males that started to call when stimulated with song composed from signals with longer duration was not significantly higher (Ryan's test, $P=n s$ ). The duration of emitted male courtship songs did not differ significantly among treatments (Kruskal-Wallis test, $H=1.59$, $d f=3$, $P=\mathrm{ns}$; Figure 3B). Compared to unaltered female calling song, significantly fewer males started to search when stimulated with a female song composed from signals with shorter duration (Figure 3C). However, none of the other measured male behavioural parameters was significantly affected by changes in the temporal parameters of female calling song. Neither searching latency $(H=0.96, d f=3, P=n s)$, search time $(H=4.53$, $\mathrm{df}=3, P=\mathrm{ns})$, nor ability to locate the source $\left(X^{2}=2.38\right.$, 
A
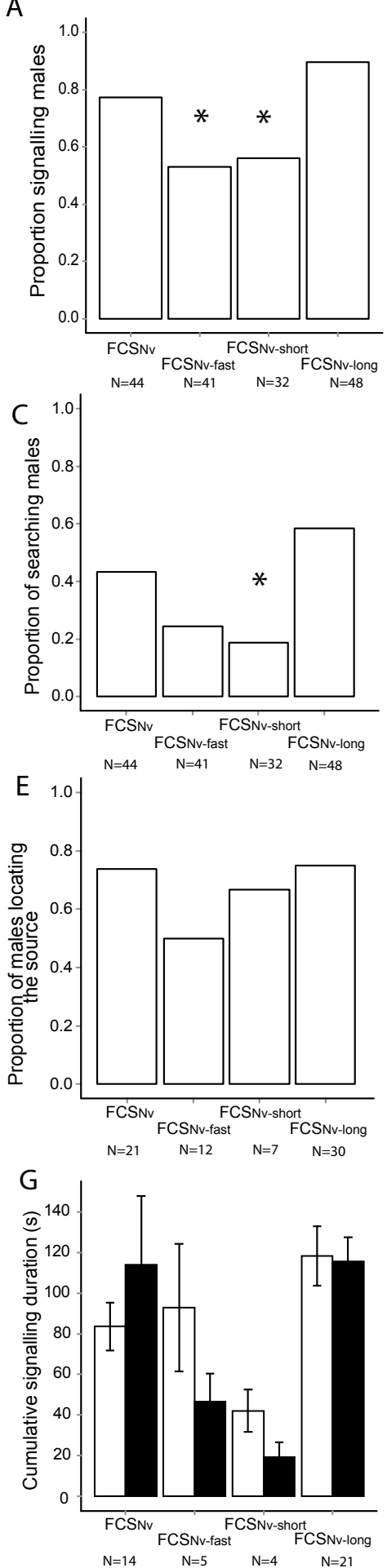

B
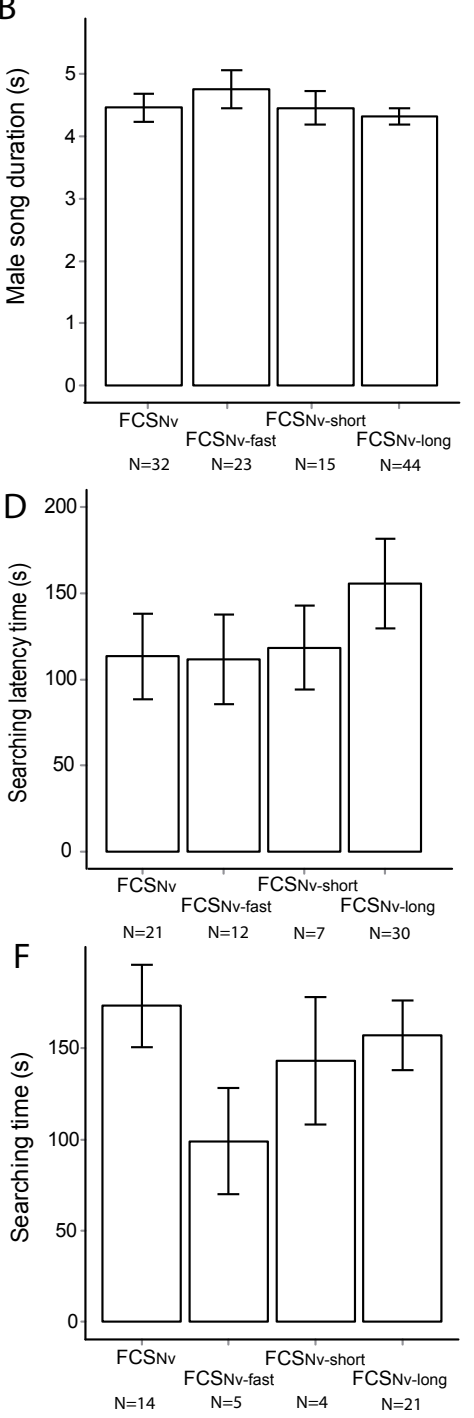

Figure 3. The effect of different temporal parameters of female calling song on the emission of male coursthip signals and searching behaviour of Nezara viridula males. (A) proportion of calling males; (B) duration of male courtship signal; (C) proportion of searching males; (D) search latency; (E) proportion of males locating the vibration source; (F) searching time. $(G)$ shows the cumulative signalling time that vibrations of males (black column) and females (white column) were present from the beginning of stimulation until males located the vibrational source (i.e. females). In C, D and F means \pm s.e.m. are shown. * indicate significant differences in comparison with the treatment with the female calling song with natural parameters $(P<0.05)$. Statistical tests: $\mathrm{A}, \mathrm{C}, \mathrm{E}-\mathrm{Chi}$-square test for contingency tables followed by Ryan's multiple comparison test of proportions; B, D, F, G - Kruskal-Wallis test followed by the Steel multiple comparison test. 

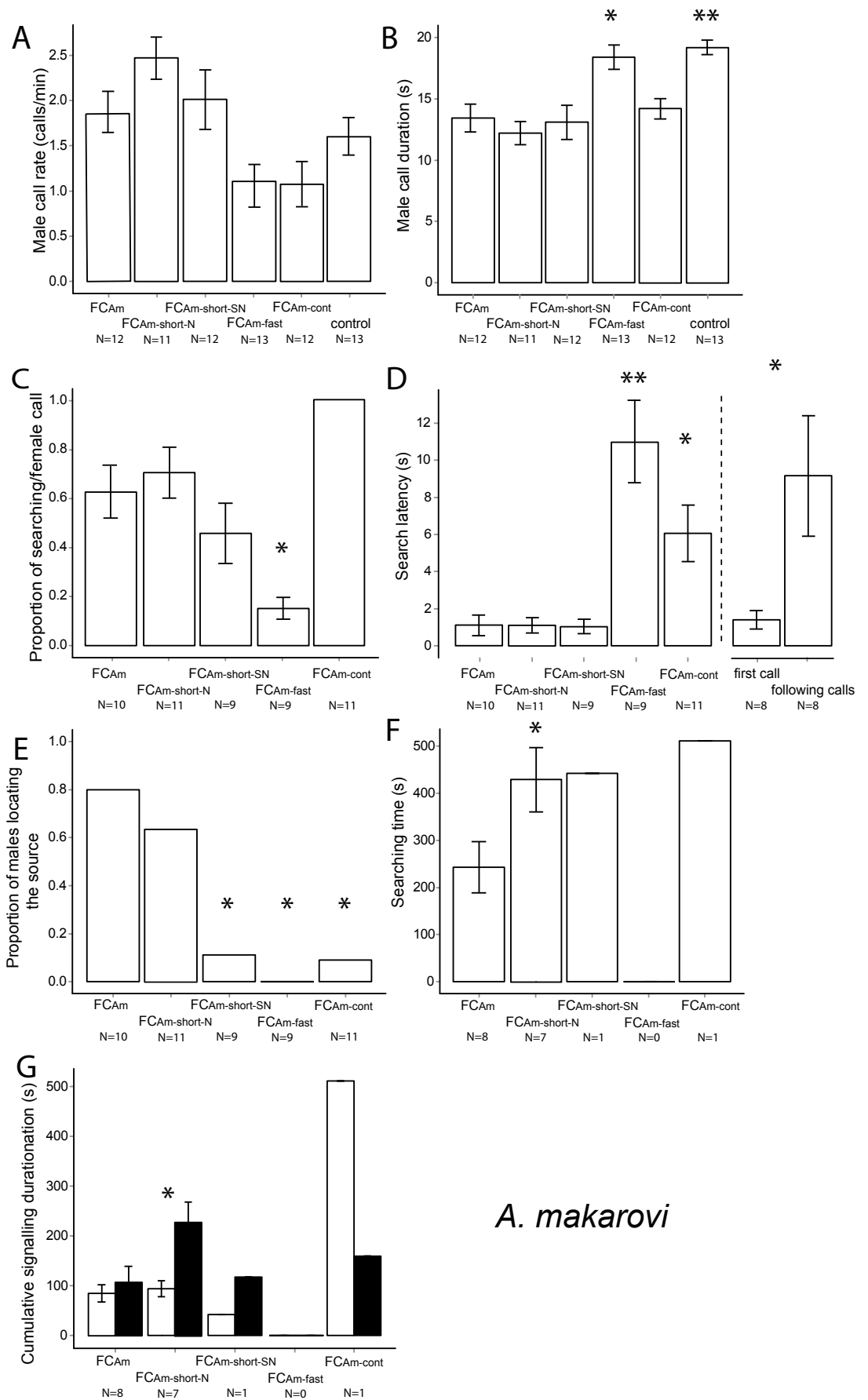

\section{A. makarovi}

Figure 4. The effect of different temporal parameters of female reply on calling and searching behaviour of $A$. makarovi males. (A) male calling rate (call/minute); (B) duration of male calls; (C) proportion of searching males per female call; (D) search latency; ( $(E)$ proportion of males locating the vibration source; (F) searching time. (G) shows the cumulative signalling time that vibrations of males (black column) and females (white column) were present from the first presented female reply until males located the vibrational source (i.e. females). In (D) the inset shows separately the search latency for the first presented female reply and the following ones. Note that in (C) the proportion of males searching for the source of continuous female reply is 1 , because all males searched, however there was only one female call present throughout the trial. In A, B, C, D and F means for each individual male \pm s.e.m. are shown. * and ** indicate significant differences in comparison with the treatment with the female calling song with natural parameters $(\mathrm{P}<0.05$ and $\mathrm{P}<0.01$, respectively). In $(F)$ and $(G)$ only treatments with natural parameters of female call $\left(\mathrm{FC}_{\mathrm{Am}}\right.$ and $\left.\mathrm{FC}_{\mathrm{Am}-\mathrm{shor}-\mathrm{N}-\mathrm{s}}\right)$ were included in the analyses. Statistical tests: A, B, C, D - Kruskal-Wallis test followed by the Steel multiple comparison test: $\mathrm{E}$ - Chi-square test for contingency tables followed by Ryan's multiple comparison test of proportions; F - Mann Whitney $U$ test; G-Wilcoxon matched-pairs signed-ranks test. In D, search latency between the first female reply and the following ones (inset) was compared with Wilcoxon matched-pairs signed-ranks test. 
$\mathrm{df}=3, P=\mathrm{ns}$ ) differed significantly between treatments (Figure 3D-F).

In none of the treatments was the cumulative signalling duration that males needed to locate the female significantly longer than for a female (Wilcoxon matched-pairs signed-ranks test, FCS: $Z=-1.29$, $\mathrm{df}=1, P=\mathrm{ns}$; fast: $Z=0.67, \mathrm{df}=1, P=\mathrm{ns}$; short: $Z=0.67$, $\mathrm{df}=1, P=\mathrm{ns}$; long: $Z=-0.36$, $\mathrm{df}=1, P=\mathrm{ns}$ ) (Figure $3 \mathrm{G}$ ). The cumulative signalling duration for males differed significantly among treatments $(H=15.73, \mathrm{df}=3, P<0.01)$ and it was significantly shorter when males were presented with female calling song composed of signals with shorter-than- natural duration (Steel test, $P<0.05$ ). Although for females the cumulative signalling duration differed significantly between different stimulation sequences $(H=9.25, d f=3, P<0.05)$, Steel test didn't reveal any significant differences suggesting, that values in treatments with modified female calling song do not differ from cumulative signalling duration in the treatment with unaltered female calling song.

\subsection{Aphrodes makarovi}

Males responded to a female reply presented in response to his calls with immediate locomotion. Males were searching only during female reply and after the female call ended, males stopped and called again. None of the male calls was emitted while males were walking. From the starting position on the top of the plant, the searching males were running fast down the stem (i.e. in the direction of the vibrational source). When they passed the leaf junction, they started to call again. In response to the applied female reply, they turned around and continued running up the stem (i.e. in the direction of the vibrational source). Males did not stop and call at the junction between the main stem and leaf stalks; instead they continued running up and down the main stem until they moved to the vibrated leaf, where they either stopped at the point where the vibrational exciter was attached to the leaf or they continued searching on the vibration exciter or on the leaf. In control experiments, males also continued calling in the absence of female reply and on average they emitted 22 calls within 13 minutes. Sixty percent of the males were also changing their position on the plant during control experiments however, in the allotted time only one leafhopper reached the vibration exciter, while the others were walking up and down the main stem. Three out of 13 males jumped from the plant before the end of the control trial (mean $=531$ seconds, s.e.m. $=125 \mathrm{~s}$ ).

The number of calling males differed significantly among treatments $\left(x^{2}=22.39, \mathrm{df}=3, P<0.001\right)$. There were significant differences in the male calling rate among treatments $(H=15.495, \mathrm{df}=5, \quad P<0.01)$. Compared to the treatment with $\mathrm{FC}_{\mathrm{Am}}$, there was no significant difference in male calling rate in other treatments $(P=2.245, P=0.95, P=0.34, P=0.20, P=0.98$ for $\mathrm{FC}_{\mathrm{Am}}, \mathrm{FC}_{\mathrm{Am} \text {-short-N }}, \mathrm{FC}_{\text {Am-short-SN }}, \mathrm{FC}_{\mathrm{Am} \text {-fast }}, \mathrm{FC}_{\text {Am-cont }}$ and control, respectively) (4A). However, in comparison with the shorter call within natural parameters $\left(\mathrm{FC}_{\text {Am-short-N }}\right)$, males called significantly less in the presence of a continuous female reply (Steel test, $P<0.05)$ and when pulse repetition rate within the female reply was higher than natural value (Steel test, $P<0.01)$. Duration of male calls differed significantly between treatments $(H=29.69, \mathrm{df}=5, P<0.001)$ and male calls were significantly longer in control trials (i.e. in the absence of female reply) (Steel test; $P<0.01$ ) and when pulse repetition time within female reply was shorter than observed species-specific value (Steel test; $P<0.05$ ) (Figure 4B). All measured parameters of male searching behaviour were significantly affected by changes in temporal parameters of the applied female reply. Taking into account the number of presented female replies, the proportion of searching males per female reply differed significantly among treatments $(H=14.98, \mathrm{df}=4, P<0.005)$. In comparison with female calls with natural parameters, the proportion of searching males per female reply was significantly lower when males were presented with a female call with higher pulse repetition time (Steel test, $P<0.05$ for both, $\mathrm{FC}_{\mathrm{Am} \text {, }}$ and $\mathrm{FC}_{\mathrm{Am} \text {-short-N}}$ ) (Figure $4 \mathrm{C}$ ). Search latency differed significantly between treatments $(H=26.69$, $\mathrm{df}=4, P<0.001)$ and in comparison with response to both female replies with natural parameters, males needed significantly more time to initiate search after female call with higher pulse repetition rate (Steel test; $P<0.01$ ) and with a continuous signal (Steel test; $P<0.05$ ) (Figure 4D). In the presence of a continuous female reply, the search latency after the first male call (i.e. female reply) was shorter than the latency after the following calls (Wilcoxon matched-pairs signedranks test, $Z=-2.52, \mathrm{df}=1, P<0.05$ ) (Figure 4D). The temporal parameters of the female reply significantly affected the number of males locating the source $\left(X^{2}=17.15, \mathrm{df}=4, P<0.001\right)$. Significantly more males located the source when they were presented with the female replies within the determined natural variation of duration of female call than in other three treatments (Ryan's tests for both, $\mathrm{FC}_{\mathrm{Am}}$, and $\mathrm{FC}_{\mathrm{Am}-\mathrm{shor}-\mathrm{N}}, P<0.05$ ). None of the males located the source of female call with pulse repetition time higher than natural values, while only one male located the source of either shorter or longer than natural female reply (Figure 4E). This corresponds to the number of leafhoppers arriving at the vibration exciter in no-stimulus conditions. Males 
needed significantly more time (Mann Whitney $U$ test: $U=71, \mathrm{df}=1, P<0.05)$ to locate the source of the shorter than longer female call within the natural parameters (Figure 4F).

When males were presented with a short female reply within natural values, the average cumulative signalling duration needed for location of the source (i.e. female) for a male was significantly longer than for a female (Wilcoxon matched-pairs signed-ranks test, $Z=-2.36$, $\mathrm{df}=1, P<0.05$ ) (Figure 4G). In contrast, when presented female reply was longer, the cumulative signalling duration did not differ significantly between males and females $(Z=-1.12, \mathrm{df}=1, P=\mathrm{ns})$. The cumulative signalling duration for males differed significantly between two treatments $(U=17, \mathrm{df}=1, P<0.05)$, while for females, the cumulative signalling duration did not differ between shorter and longer calls $(U=45, \mathrm{df}=1, P=\mathrm{ns})$.

\section{Discussion}

Our results confirm the hypothesis that according to differences in communication system between $N$. viridula and $A$. makarovi, changes in temporal parameters of female signals have different effect on the males of each species. In A. makarovi (i.e. in a bidirectional vibrational communication system), a duet enabled a faster onset of male searching behaviour than in N. viridula (i.e. in a unidirectional system). In $N$. viridula males needed on average around $2 \mathrm{~min}$ to commence searching, while in $A$. makarovi the mean search latency was around $1 \mathrm{~s}$ and the shortest observed latency was $0.24 \mathrm{~s}$. However, after searching was triggered, in unidirectional system males of $N$. viridula successfully located also the source of a female song with parameters outside the speciesspecific values. In contrast, males of $A$. makarovi failed to locate the source of a female reply that was either shorter or longer than natural values or with pulse repetition time outside the species-specific value. According to the prediction, in A. makarovi longer female reply provided better directional information and males located such a source significantly faster. In N. viridula, males located faster the female song with higher signal repetition time however, differences were not significant.

In $A$. makarovi, a stereotyped and predictable temporal association between male and female call suggests that female reply may have to appear within a critical time window to ensure recognition and trigger male searching behaviour. Duetting phaneropterine bush crickets females recognize conspecific males on the basis of the temporal parameters of their calls, while female reply within the species-specific time window provides the key element to identify the female $[10,27,43]$. Critical time window of the female reply has also been demonstrated in bioluminescent communication systems found in fireflies (Coleoptera, Lampyridae) $[44,45]$ and in vibrational communication of the alderfly genus Sialis (Neuroptera, Sialidae) [46]. However, if in $A$. makarovi only a response time window is essential for species recognition and triggering male searching behaviour, other temporal parameters of the female call would not have any effect on the male response. In A. makarovi, a female reply with pulse repetition time outside the species-specific value had a significant negative effect on all measured parameters of male searching behaviour. Furthermore, the duration of a female reply also had a significant effect on searching behaviour of $A$. makarovi male. While female replies shorter than observed natural species-specific values had significant negative effect only on males' ability to localize the source of vibrational signal in the allotted time, a continuous female signal had a negative effect also on the recognition of a female signal. This indicates that stereotyped temporal association between initiating male call and a female reply may only one of the factors important for the recognition of female vibrational signal.

Incidental interference from heterospecific signals is common in vibrational communication [38] and high selectivity for species-specific temporal parameters may also suggest that the potential costs for searching for a heterospecific female may be high $[47,48]$. Communication system of $A$. makarovi may have evolved in low relative abundance of conspecifics [49]. In such situation receivers should become highly selective in their response however, they would face additional costs of longer time spent in finding the correct partner. In the field several closely related species in genus Aphrodes are often found syntopically and they can even share the same host plants (VirantDoberlet, personal observation). Furthermore, female vibrational signals in this genus differ primarily in their duration and pulse repetition time (Bluemel et al., in preparation). At present there is not enough information whether such high selectivity for speciesspecific temporal parameters of female vibrational signals may be a common characteristic of bidirectional vibrational communication systems or applies only to closely related species that live syntopically. Since in phaneropterine bushcrickets female replies are unspecific and usually composed of only one short element, there is no information about the influence of other parameters of female reply on recognition by males. However, in genus Sialis, female reply has to be above critical length and within relevant frequency range [46]. In gomphocerine grasshoppers recognition of species-specific signal relies on song parameters 
that are common to both sexes [50] however, males are less selective than females and even court heterospecific females [51]. Although constant latency of the female reply has not been reported for planthoppers of the genus Ribautodelphax [52,53], in males of $R$. imitans searching behaviour was triggered only by playback reply of a conspecific female [53]. As in leafhopper genus Aphrodes, in Ribautodelphax planthoppers species-specificity of female vibrational signals is found in pulse repetition time and duration of female call [52]. However, male signals in genus Ribautodelphax contain similar sound elements [52] and females often responded also to vibrational calls of heterospecific males [53]. In contrast, male calls in genus Aphrodes are highly species-specific [33,34] (Bluemel et al., in preparation) and females show high selectivity for conspecific male signals (Derlink et al., in preparation). Further detailed studies are needed to unequivocally determine the presence of male's sensitive time window in $A$. makarovi and to elucidate the roles of the timing and temporal structure of female response in recognition of conspecific female.

One of the factors that affects selectivity and searching effort in males is male mating investment $[47,48]$. While copulation in $N$. viridula can last up to seven days [54], Aphrodes leafhoppers stay in copula for up to 15 minutes (Virant-Doberlet, pers obs.). Furthermore, as in other leafhopper species, A. makarovi females mate only once, while females of $N$. viridula mate several times, frequently immediately after the termination of one copulation [54,55]. In systems like in A. makarovi, where female fitness peaks at a small number of matings, males may experience very high search costs arising from prolonged searching time and should benefit by courting every receptive conspecific female they encounter [48]. This prediction corresponds well to the mate searching behaviour observed in male $A$. makarovi. Males of $A$. makarovi face greater predation risk, not only because of the higher mobility needed to expand their signalling space they may increase encounter rate with predators [56], but also because eavesdropping predators use their vibrational signals as a cue during foraging and, as a result, kill more males than females [57]. Results of the present study show that $A$. makarovi males were not choosy and almost all males (86\%) were searching for the source of those tested vibrational signals that were within species-specific parameters.

In contrast, males of $N$. viridula may have similar mating costs to those of females, due to long copulation duration. Under such conditions, males may benefit by being choosy however, such strategy should offer the greatest advantage only when costs of searching and assessment are low [48]. Males of $N$. viridula increase the probability of encounter rate with conspecific females by attracting them to the same plant by sex pheromones [58] and in comparison with A. makarovi, in $N$. viridula mobility of males is related mainly to localized search for a continuously singing female. Males are often attacked by the parasitoid fly Trichopoda pennipes that is attracted to male sex pheromone [59]. The longterm cost of being parasitized however, is not directly comparable to the immediate cost of being eaten by a predator. It has been shown in the closely related species T. giacomellii that during the 16 day period of larval parasitoid development male fertility and mating frequency is not impaired [60]. In the present study male choosiness was expressed in relatively low proportion of males searching for the vibrational source (i.e. males rejected mating opportunities $[47,48])$.

The most prominent difference between investigated species was found in the effect of differences in temporal parameters of female signals on males' success in locating the source of female vibrational signal. Since the main role of signals used in sexual communication is to bring together prospective partner [10], a failure to locate the female would result in a reduced reproductive success of a male. In $N$. viridula male and female vibrational signals are of similar complexity [18] and it is likely that energetic costs of signal production for males and female are the same. Taking into account the cumulative time that males and females spent signalling (for females the cumulative duration of female signal in stimulation sequence) before males located the source of vibrations, our results indicate that energy cost invested in signal production would not be significantly different for males and females. In contrast, in A. makarovi female signals are less complex and have lower amplitude (de Groot et al., submitted for publication) and it is likely that energy investment in signal production is, in general, higher in males than in females. However, while for females the cumulative signalling time invested in pair formation did not differ between shorter and longer replies, for males signalling time was reduced, as a result of faster localization of a female. These results suggest that by increasing the duration of her reply, for no additional personal cost, a female may contribute to reducing the costs of male searching effort. It has been shown that females of $A$. makarovi varied the duration of their reply according to duration of the male call to which they were responding (de Groot et al., submitted for publication). In communication system in which duration of the female reply may be crucial for quick localization of the female, variation in duration may indicate female preference and choice. Further detailed studies are needed to elucidate the relations between investments 
of males and female in pair formation in unidirectional and bidirectional vibrational communication system.

Another factor which can influence the male searching behaviour is male-male competition [48]. Satellite behaviour (eavesdropping by silent males on male-female duets) $[61,62]$ or disrupting the ongoing duet $[63,64]$ is a common phenomenon among insects using air-borne sound communication. In unidirectional vibrational communication system as present in $N$. viridula, satellite males would have no distinct advantage, since female song is constantly present and all males present on the same plant have equal chance for locating her. Male rivalry signals have been described in $N$. viridula [18] and they are supposed to disrupt male-female communication when insects are already in vicinity of each other [17]. In contrast, eavesdropping should be advantageous in bidirectional communication system as observed in $A$. makarovi, in particular, if silent satellite males move around and search for a female already while the male initiating a duet is stationary during singing. It has been shown in the leafhopper species Scaphoideus titanus that intruding silent males search while the stationary courting male is maintaining a duet with a female and that satellite males orient specifically towards a duetting female $[29,65]$. In this species it has been proposed that shortening of the male vibrational signal after the courting male perceived the presence of a rival is a defensive tactic that enables to reduce the time needed for localization. In A. makarovi the duration of male calls was significantly reduced also in natural duets with live females (de Groot et al., submitted for

\section{References}

[1] Parker G.A., Sexual selection and sexual conflict. In: Blum M.S., Blum N.A. (Eds). Sexual selection and reproductive competition in insects, Academic Press, New York, 1979

[2] Real L., Search theory and mate choice. I. Models of single-sex discrimination, Am. Nat., 1990, 136, 376-405

[3] Guevara-Fiore P., Stapley J., Krause J., Ramnarine I.W., Watt P.J., Male mate-searching strategies and female cues: how do male guppies find receptive females?, Anim. Behav., 2010, 79, 1191-1197

[4] Shuster S.M., Wade M.J., Mating systems and strategies, Princeton University Press, Princeton, 2000

[5] Andersson M., Sexual selection, Princeton, New Jersey, Princeton University Press, 1994

[6] Kokko H., Wong B.B.M, What determines sex roles in mate searching?, Evolution 2007, 61, 1162-1175

[7] Byers J.A., Wiseman P.A., Jones L., Roffe T.J., A large cost of female mate sampling in pronghorn, Am. Nat., 2005, 166, 661-668. publication). However, male calling strategy to reduce the duration of the call after an initial contact with the female has been established to reduce risks imposed by predators and sexual competitors may be in conflict with female preferences expressed in duration of female reply which enables faster localization. Further studies should provide more insight into the mechanisms that are involved in male-male competition and how alternative tactics influence male searching behaviour in unidirectional and bidirectional communication system. The role of male rivalry behaviour in vibrational communication is, in general, largely unexplored.

The present study has provided the first comparison between two common forms of communication systems used in vibrational communication and should serve as a foundation for further and more detailed studies. Since substrate-borne sound communication is prevalent in insects [13], it is likely that further studies including wider range of species and groups may reveal many important interactions that influenced the evolution of vibrational communication as well as provide valuable insight in communication in general.

\section{Acknowledgments}

The work was supported by funding from the Slovenian National Research Agency (PhD fellowship 1000-07310030 and Research Program P1-0255). We wish to thank Dr. Alenka Žunič for technical help, and Dr. Andrej Blejec for interesting discussions about statistics.

[8] Zuk M., Kolluru G.R., Exploitation of sexual signals by predators and parasitoids, Quaterly Rev. Biol., 1998, 73, 415-438.

[9] Bradbury J.W., Vehrencamp S.L., Principles of animal communication, Sinauer Associates, Sunderland (MA), 1998

[10] Gerhardt H.C., Huber F., Acoustic communication in insects and anurans: common problems and diverse solutions, University of Chicago Press, Chicago, 2002

[11] Greenfield M.D., Signallers and receivers: mechanisms and evolution of arthropod communication, Oxford University Press, New York, 2002

[12] Virant-Doberlet M., Čokl A., Vibrational communication in insects, Neotrop.Entomol., 2004, 33, 121-134

[13] Cocroft R.B., Rodríguez R.L., The behavioral ecology of insect vibrational communication, BioScience, 2005, 55, 323-334 
[14] Dietrich C.H. Auchenorrhyncha (Cicadas, spittlebugs, leafhoppers, treehoppers, and planthoppers, In: Resh V.H., Cardé R.T. (Eds.), Encyclopedia of insects, $2^{\text {nd }}$ ed., Academic Press, London, 2009

[15] Schaefer C.W., Prosorrhyncha (Heteroptera and Coleorrhyncha), In: Resh V.H., Cardé R.T. (Eds.), Encyclopedia of insects, $2^{\text {nd }}$ ed., Academic Press, London, 2009

[16] Gullan P.J., Martin J.H. Sternorrhyncha (jumping plant-lice, whiteflies,aphids, and scale insects), In: Resh V.H., Cardé R.T. (Eds.), Encyclopedia of insects, $2^{\text {nd }}$ ed., Academic Press, London, 2009

[17] Čokl A., Stink bug interaction with host plants during communication, J. Insect. Physiol., 2008, 54, 1113-1124

[18] Čokl A., Virant-Doberlet M., Stritih N, The structure and function of songs emitted by southern green stink bugs from Brazil, Florida, Italy and Slovenia, Physiol. Entomol., 2000, 25, 196-205

[19] Čokl A., Virant-Doberlet M., McDowell A., Vibrational directionality in the southern green stink bug Nezaraviridula(L.) is mediated by female song, Anim. Behav., 1999, 58, 1277-1283

[20] Miklas N., Stritih N., Čokl A., Virant-Doberlet M., Renou M., The influence of substrate on male responsiveness to the female calling song in Nezaraviridula, J Insect. Behav., 2001, 14, 313-332

[21] Miklas N., Čokl A., Renou M. and Virant-Doberlet M., Variability of vibratory signals and mate choice in the southern green stink bug, Behav.Process., 2003, 61, 131-142

[22] Hrabar N., Virant-Doberlet M, Čokl A., Species specificity of male southern green stink bug Nezaraviridula(L.) reactions to female calling song, Acta Zool Sin., 2004, 50, 566-575

[23] Miklas N., Interactions and changes of acoustic and olfactory signals during the meeting of the sexes in Nezaraviridula(Heteroptera, Pentatomidae), [Interactions et variations des signau xacoustiques et olfactifs lors de la rencontre des sexes chez Nezaraviridula(Heteroptera, Pentatomidae)], PHD thesis,L'Universite Paris XIII, Paris, 2002, (in French)

[24] Polajnar J, ČokIA., The effect of vibratory disturbance on sexual behaviour of the southern green stink bug Nezaraviridula(Heteroptera, Pentatomidae), Centr. Eur. J. Biol., 2008, 3, 189-197

[25] Claridge M.F., Acoustic signals in the Homoptera: behaviour, taxonomy, and evolution, Annu. Rev. Entomol., 1985, 30, 297-317

[26] Čokl A., Virant-Doberlet M., Communication with substrate-borne signals in small plant-dwelling insects, Annu. Rev. Entomol., 2003, 48, 29-50
[27] Bailey W.J. Insect duets: underlying mechanisms and their evolution, Physiol. Entomol., 2003, 28, 157-174

[28] Virant-Doberlet M., Čokl A., Zorović M., Use of substrate vibrations for orientation: from behaviour to physiology. In: Claridge M.F., Drosopoulos S., (eds) Insect sounds and communication: physiology, behaviour, ecology and evolution, Taylor \& Francis, Boca Raton, 2006

[29] Mazzoni V., Prešern J., Lucchi A., Virant-Doberlet M., Reproductive strategy of the Nearctic leafhopper Scaphiodeustitanus Ball (Hemiptera: Cicadellidae), Bull. Entomol. Res., 2009, 99, 401-413

[30] De Vrijer P.W.F., Species distinctiveness and variability of acoustic calling signals in the planthopper genus Javesella (Homoptera: Delphacidae), Neth. J. Zool., 1986, 36, 388-406

[31] Gwynne D.T., Sex-baised predation and the risky mate-locating behaviour of male tick-tock cicadas (Homoptera, Cicadidae), Anim. Behav., 1987, 35, 571-576

[32] Hunt R.E., Nault L.R., Roles of interplant movement, acoustic communication, and phonotaxis in mate-location behavior of the leafhopper Graminellanigrifrons,Behav. Ecol. Sociobiol., 1991, 28, 315-320

[33] Tishechkin D.Y., Acoustic signals and morphological characters of leafhoppers from Aphrodesbicinctus group from central European Russia, ZoologicheskyZhurnal, 1998, 77, 669-676

[34] Tishechkin D.Y., Vibrational communication in Aphrodinae leafhoppers (Deltocephalinae act., Homoptera: Cicadellidae) and related groups with notes on classification of higher taxa, Russian Entomol. J., 2000, 9, 1-66

[35] Panizzi R. A.,Wild hosts of pentatomids: ecological significance and role of their pest status on crops, Annu. Rev. Entomol. 1997, 42, 99-122

[36] Čokl A., Gogala M., Blaževič A., Principles of sound recognition in three pentatomidae bug species, Biol. Vestn., 1978, 26, 81-94

[37] Žunič A., Virant-Doberlet M., Čokl A., Species recognition during substrate-borne communication in Nezaraviridula (L.) (Pentatomidae: Heteroptera), J. Insect Behav., 2011, DOI: 10.1007/s10905-0119272-x

[38] de Groot M., Čokl A., Virant-Doberlet M., Effects of heterospecific and conspecific signal overlap and signal-to-noise ratio on male responsiveness in Nezaraviridula(L.), J. Exp. Biol., 2010, 213, 3213-3222

[39] Quinn G. P., Keough M.J., Experimental design and data analysis for biologists., Cambridge University Press, Cambridge, 2002. 
[40] Ryan J.A., Significance test for multiple comparison of proportions, variances and other statistics, Physiol. Bull, 1960, 57, 318-328

[41] Steel R.D.G., A multiple comparison rank test: treatments versus control, Biometrics, 1959, 15, 560-572

[42] Ota D., Čokl A., Mate location in the southern green stink bug Nezaraviridul (Heteroptera: Pentatomidae) mediated through substrate-borne signals on ivy, J. Insect. Behav., 1991, 4, 441-447

[43] Heller K.G., von Helversen D. Acoustic communication in phaneropterid bush crickets: species-specific delay of female stridulatory response and matching male sensory time window, Behav. Ecol. Sociobiol., 1986, 18, 189-198

[44] Buck J., Case J., Physiological links in firefly flash code evolution, J. Insect Behav., 2002, 15, 51-68

[45] Lewis S.M., Cratsley C.K., Flash signal evolution, mate choice, and predation in fireflies, Annu. Rev. Entomol., 2008, 53, 293-321

[46] Rupprecht R., The communication of Sialis (Megaloptera) through vibrational signals, [Die Kommunikation von Sialis (Megaloptera) durch Vibrationssignale], J. Insect Physiol., 1975, 21, 305-320 (in German)

[47] Johnstone R.A., Reynolds J.D., Deutsch J.C., Mutual mate choice and sex differences in choosiness, Evolution, 1996, 50, 1382-1391

[48] Bonduriansky R., 2001. The evolution of male mate choice in insects: a synthesis of ideas and evidence, Biol. Rev., 76, 305-339

[49] Wiley $\mathrm{RH}$., Errors, exaggeration and deception in animal communication, In: Real L, (ed.) Behavioral mechanisms in ecology, University of Chicago Press, Chicago, 1994

[50] von Helversen D., Acoustic communication and orientation in grasshoppers, In: Lehrer M. (Ed.), Orientation and communication in arthropods, BirkhäuserVerlag, Berlin, 1997

[51] von Helversen D., von Helversen O., Recognition of sex in the acoustic communication of the grasshopper Chorthippusbiguttulus (Orthoptera, Acrididae), J. Comp. Physiol. A, 1997, 180, 373-386

[52] Den Bieman C.F.M., Acoustic differentiation and variation in planthoppers of the genus Ribautodelphax (Homoptera, Delphacidae), Neth. J. Zool., 1986, 36, 461-480.

[53] De Winter A. J., Rollenhagen T., The importance of male and female acoustic behaviour for reproductive isolation in Ribautodelphaxplanthoppers (Homoptera: Delphacidae), Biol. J. Linn. Soc., 1990, 40, 191-206
[55] Harris V.E., Todd J.W., Temporal and numerical patterns of reproductive behaviour in the southern green stink bug Nezaraviridula(Hemiptera: Pentatomidae), Entomol. Exp. Appl., 1980, 27, 105-116

[54] McLain D.K., Female choice and the adaptive significance of prolonged copulation in Nezaraviridula (Hemiptera: Pentatomidae), Psyche, 1980, 87, 325-336

[56] Burk T. Evolutionary significance of predation on sexually signalling males, FI. Entomol., 1982, 65, 90-104

[57] Virant-Doberlet M., King R.A., Polajnar J., Symondson W.O.C., Molecular diagnostics reveal spiders that exploit prey vibrational signals used in sexual communication, Mol. Ecol., 2011, 20: 22042216

[58] Borges M., Jepson P. C., Howes P. E., Longrange mate location and close-range courtship behaviour of the green stink bug Nezaraviridulaand its mediation by sex pheromones, Entomol. Exp. Appl.,1987, 44, 205-212

[59] Harris V.E., Todd J.W., Male-mediated aggregation of male, female and 5th instar southern stinkbugs, Nezaraviridula (L) (Hemiptera, Pentatomidae) and concomitant attraction of a tachanid parasite, TrichopodapennipesDiptera, Tachanidae, Entomol. Exp. Appl., 1980, 27, 117-126

[60] Coombs M., Khan S., Fecundity and longevity of green vegetable bug, Nezaraviridula, following parasitism by Trichopodagiacomellii, Biol. Control, 1998, 12, 215-222

[61] Ott, J.R. An ecological framework for the study of planthopper mating systems. In: Denno, R.F., Perfect, R.J. (Eds.), Planthoppers: their ecology and management, Champan\& Hall, New York, 1994.

[62] Donelson N.C., van Staaden M.J., Alternative tactics in male bladder grasshoppers Bullacrismembracioides (Orthoptera: Pneumoridae), Behaviour, 2005, 142, 761-778.

[63] Gross, M.R., Alternative reproductive strategies and tactics: diversity within sexes, Trends Ecol. Evol., 1996, 11, 92-98.

[64] Bailey W.J., Field G. Acoustic satellite behaviour in the Australian bushcricketElephantodetanobilis (Phaneropterinae, Tettigoniidae, Orthoptera), Anim. Behav., 2000, 59, 361-369

[65] Mazzoni V., Lucchi A., Čokl A., Prešern J., VirantDoberlet M., 2009, Disruption of the reproductive behavior of Scaphoideustitanus by playback of vibrational signal, Entomol. Exp. Appl., 133, 174185 